\title{
Hot Tensile Deformation and Fracture Behavior of a Nitrogen Alloyed Ultralow Carbon Austenitic Stainless Steel
}

\author{
Xiaoya Yang ${ }^{1}$, An $\mathrm{He}^{1}$, Shilei $\mathrm{Li}^{1}$, Hailong Zhang ${ }^{1}$ and Xitao Wang ${ }^{1,2}$ \\ ${ }^{1}$ State Key Laboratory for Advanced Metals and Materials, University of Science and Technology Beijing, \\ Beijing 100083, P. R. China \\ ${ }^{2}$ Collaborative Innovation Center of Steel Technology, University of Science and Technology Beijing, \\ Beijing 100083, P. R. China
}

The hot tensile deformation and fracture behavior of a nitrogen alloyed ultralow carbon austenitic stainless steel were studied by a Gleeble$1500 \mathrm{D}$ thermo-mechanical simulator with the temperature range of $1173-1473 \mathrm{~K}$ and strain rate range of $0.01-1 \mathrm{~s}^{-1}$. Microstructural evolution was analyzed in terms of fractography at various deformation temperatures and strain rates. The tensile true stress-true strain curves after necking were calculated by the heuristic method. The fracture threshold values of the studied steel were estimated by finite element method (FEM). The final load-stroke curves obtained from the FEM simulation were found to have a good agreement with the experimental load-stroke curves. The quantitative relationship between fracture threshold value and Zener-Hollomom parameter was also established. The results are beneficial to the understanding of hot deformation behavior of a wide range of stainless steels. [doi:10.2320/matertrans.M2015221]

(Received June 1, 2015; Accepted September 8, 2015; Published October 16, 2015)

Keywords: stainless steel, hot deformation, fracture threshold value, finite element method, fractography

\section{Introduction}

Nitrogen alloyed ultralow carbon austenitic stainless steel is a good candidate material for the primary piping of AP1000 nuclear power plant, due to its good corrosion resistance, excellent mechanical performance and adequate weldability. Figure 1 shows the schematic diagram of the AP1000 forging pipe with integrated nozzles. The integral forging of the pipe including two nozzles increases the difficulty of forging process. It is a main concern whether this large forging can be successfully manufactured without fracture. Currently, the forging processes of fracture-free products are designed through experience-based trial-anderror, ${ }^{1-3)}$ which is inefficient and expensive. For AP1000 forging pipes, it is nearly impossible to conduct repeated experimental forging investigations to design the forging process, owing to their large size, complex shape and high cost. Thanks to the development of finite element method (FEM), the design and optimization of such forging processes can be done by FEM, which will greatly decrease the cost and increase the efficiency. However, the task cannot be finished without comprehensive and in-depth study of fracture behavior of the nitrogen alloyed ultralow carbon austenitic stainless steel. Thus, it is imperative to investigate the fracture behavior of the steel and to develop the corresponding fracture criteria.

Many researchers have studied fracture behavior of metallic materials and have established several fracture criteria such as Freudenthal criterion, ${ }^{4)}$ Cockcroft \& Latham criterion, ${ }^{5)}$ normalized Cockcroft \& Latham criterion, ${ }^{6)}$ Brozzo criterion, ${ }^{7}$ Oyane criterion $^{8)}$ and Rice \& Tracey criterion. ${ }^{9)}$ Some of them are included in commercial finite element simulation software, this enables the prediction of fracture by finite element simulation. Dizaji et al. ${ }^{10)}$ predicted the fracture of DKP 6112 steel sheet by five different ductile fracture criteria with different hardening models and hardening rules, and they found that some ductile fracture criteria give better predictions if appropriate hardening model is employed. Zhu et al. ${ }^{11)}$ supposed a new fracture criterion that takes into consideration the effects of temperature and strain rate to predict the fracture of a Ti40 titanium alloy. Zhang et al. ${ }^{12)}$ predicted the location of crack initiation in a Ti40 alloy by FEM with the Oyane criterion. Cao et al. ${ }^{13)}$ studied three ductile damage approaches in predicting fracture in cold forming process. Ran et al. ${ }^{14)}$ supposed a hybrid model to calculate the fracture energy which considers the influence of grain size.

During hot forming of metallic materials, different fracture mechanisms will play a role, depending on deformation parameters like temperature and strain rate. ${ }^{15)}$ With increasing temperature, dynamic recrystallization will make a contribution to reducing stress concentration and to isolating microcracks originally at the grain boundaries. ${ }^{16)}$ With increasing strain rate, the time for dynamic recovery and dynamic recrystallization will reduce, which maintains stronger stress concentration and more microcracks. ${ }^{17)}$ Thus, it is necessary to understand the microstructural evolution with the change of deformation parameters as well as the effect on fracture morphology of metallic materials. There are many researches on the change of microstructure and fracture morphology with deformation parameters, for various materials such as $\mathrm{Al}-\mathrm{Zn}-\mathrm{Mg}-\mathrm{Cu}$ alloy, ${ }^{18)}$ 42CrMo steel, ${ }^{19)} \mathrm{Ti}$ alloy, ${ }^{20)} \mathrm{Mg} / \mathrm{Mg}_{2} \mathrm{Si}$ composite ${ }^{21)}$ and $\mathrm{Al}-\mathrm{Cr}-\mathrm{Cu}-$ $\mathrm{Ni}-\mathrm{Fe}-\mathrm{Co}$ high-entropy alloy. ${ }^{22}$

There are some investigations on the fracture behavior of the studied steel. Duan et al. ${ }^{23)}$ obtained the critical damage values for initiation of voids based on normalized Cockcroft \& Latham fracture criterion. Zhang et al. ${ }^{24)}$ found that recrystallization promotes the formation of cracks and stress trialxiality plays an important role in the prediction of the destruction. He et al. ${ }^{25)}$ proposed a fracture criterion based on Oyane criterion to predict the hot deformation fracture. Although these studies have been carried out, further study of the hot deformation and fracture behavior is still greatly needed in order to realize the simulation-based design and optimization of manufacturing process of primary piping for 

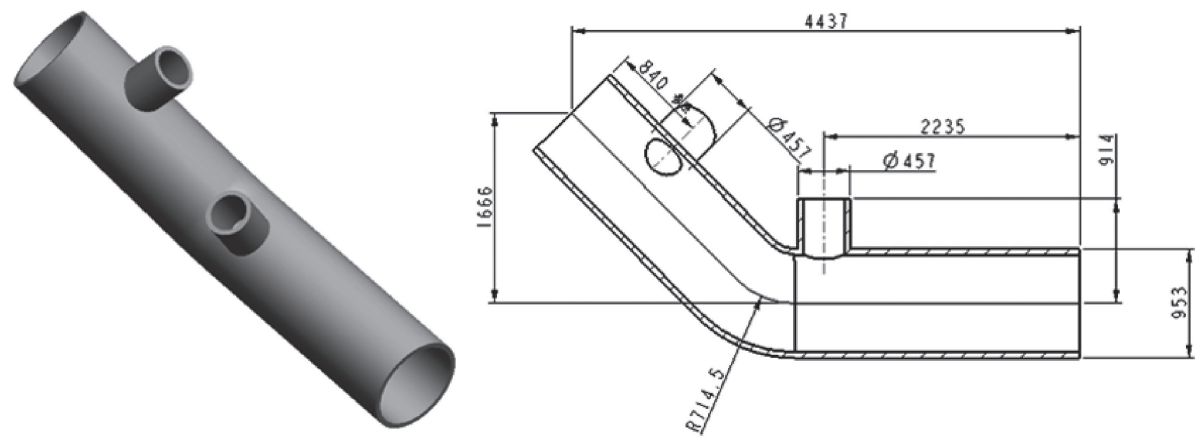

Fig. 1 Schematic diagram of the AP1000 forging pipe with two integrated nozzles.

Table 1 The chemical composition of the studied steel.

\begin{tabular}{ccccccccc}
\hline Element & $\mathrm{C}$ & $\mathrm{N}$ & $\mathrm{Cr}$ & $\mathrm{Ni}$ & $\mathrm{Mo}$ & $\mathrm{Si}$ & $\mathrm{Mn}$ & $\mathrm{Fe}$ \\
\hline mass $\%$ & 0.011 & 0.122 & 17.18 & 13.12 & 2.23 & 0.24 & 1.3 & Bal. \\
\hline
\end{tabular}

the AP1000 nuclear power plant. In this study, hot tensile experiments are conducted on a Gleeble-1500D thermomechanical simulator. The influences of deformation temperature and strain rate on the microstructures at the fracture area and the fracture morphologies are analyzed. The fracture threshold values are estimated by FEM. Especially, the quantitative relationship between fracture threshold value and Zener-Hollomom parameter is established, and the fracture threshold values of the studied steel under different hot deformation conditions can be calculated more easily and accurately.

\section{Experiment}

The chemical compositions of the studied steel are listed in Table 1. The cast ingots were solution treated at $1373 \mathrm{~K}$ for $1 \mathrm{~h}$. After that, cylindrical tensile specimens with a diameter of $10 \mathrm{~mm}$ and a height of $121.5 \mathrm{~mm}$ were machined. The initial microstructure after solution treatment is shown in Fig. 2.

The tests were carried out on a Gleeble-1500D thermomechanical simulator at four deformation temperatures of $1173,1273,1373$, and $1473 \mathrm{~K}$ and with three strain rates of $0.01,0.1$ and $1 \mathrm{~s}^{-1}$. The specimens were firstly heated to $1473 \mathrm{~K}$ at a rate of $20 \mathrm{~K} / \mathrm{s}$ and held for $300 \mathrm{~s}$ to eliminate the thermal gradients. Then, the specimens were cooled down to the specified deformation temperature at a rate of $15 \mathrm{~K} / \mathrm{s}$ and soaked for $30 \mathrm{~s}$. Subsequently, the tests started at certain temperatures and strain rates. After tensile fracture, the deformed specimens were quenched in water immediately to preserve the hot deformation microstructure. All of the deformed specimens were sectioned parallel to the tensile axis so as to observe the microstructures at fracture area by an optical microscope (OM), and the fracture morphologies were observed by a scanning electron microscope (SEM).

\section{Experimental Results}

\subsection{Microstructural evolution at fracture area}

Figure 3 shows the microstructures at fracture area of the specimens deformed at different temperatures and strain

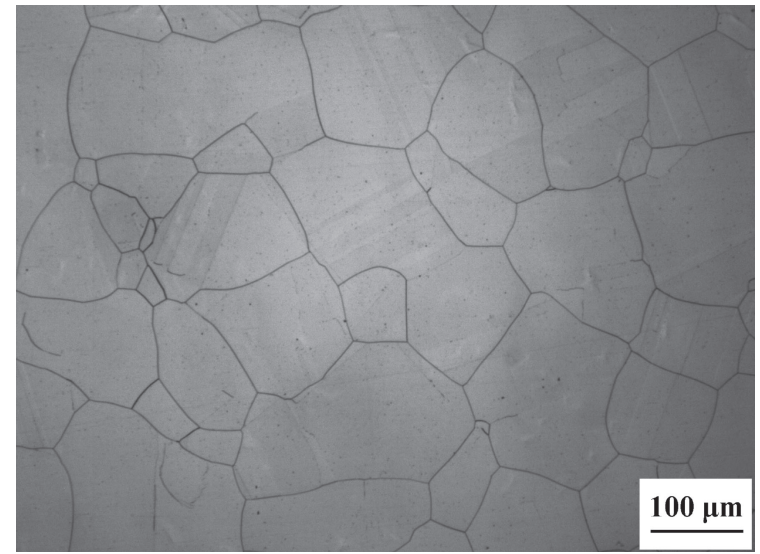

Fig. 2 Microstructure of the as-received steel.

rates. All the $\mathrm{OM}$ images were taken on sections parallel to the tensile direction.

Under the deformation temperature of $1173 \mathrm{~K}$ and the strain rate of $0.1 \mathrm{~s}^{-1}$, the initial grain boundaries are serrated and few recrystallized grains at the initial grain boundaries can be seen, which is shown in Fig. 3(a). With increasing deformation temperature, the recrystallization nucleation rate accelerates. More recrystallized grains occur at the initial grain boundaries when deformation temperature is increased from $1173 \mathrm{~K}$ to $1273 \mathrm{~K}$, as shown in Fig. 3(b). When the deformation temperature reaches $1373 \mathrm{~K}$, much more recrystallized grains are observed along the tensile direction, as shown in Fig. 3(c). At the deformation temperature of $1473 \mathrm{~K}$, the recrystallized grains grow rapidly and replace the initial grains completely, and a homogeneous microstructure is obtained, as shown in Fig. 3(d).

Under the strain rate of $0.01 \mathrm{~s}^{-1}$ and deformation temperature of $1273 \mathrm{~K}$, grain size is fine and microstructure is homogenous, as shown in Fig. 3(e). With increasing strain rate, the time for grain growth reduces, and the size of recrystallized grain becomes smaller. When the strain rate reaches $1 \mathrm{~s}^{-1}$, the recrystallized grain is extremely small, which is shown in Fig. 3(f), leading to the seriously inhomogeneous microstructure.

At the temperature of $1473 \mathrm{~K}$, with increasing strain rate, the finial microstructure at fracture area becomes finer and more homogeneous (shown in Figs. 4(a), 3(d) and 4(b)), which is different from the microstructural evolution with strain rate at the lower temperature of $1273 \mathrm{~K}$. This is because the finial recrystallization microstructure is determined by the 

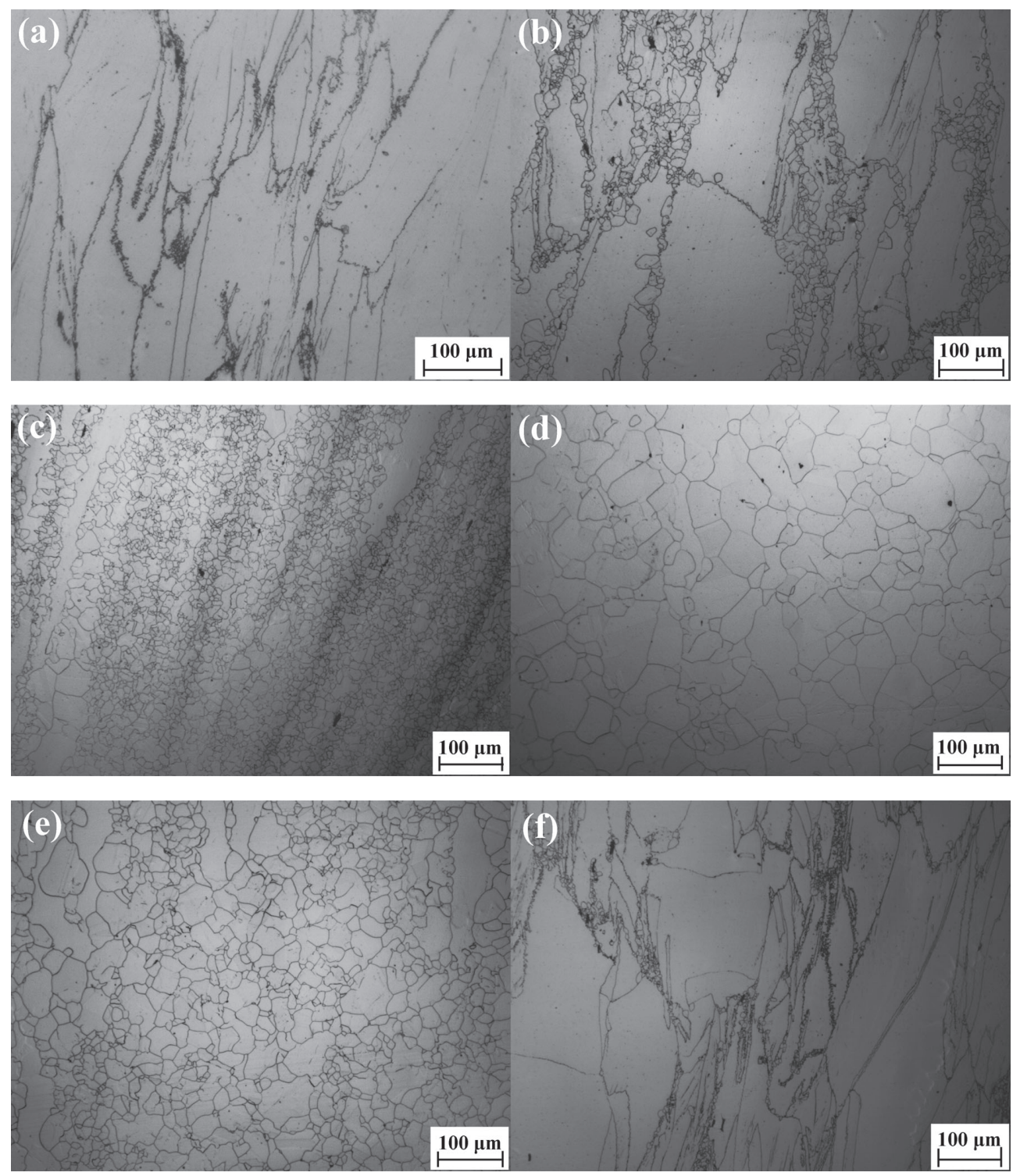

Fig. 3 Metallographic photos of the specimens at the fracture areas: (a) $1173 \mathrm{~K}, 0.1 \mathrm{~s}^{-1}$, (b) $1273 \mathrm{~K}, 0.1 \mathrm{~s}^{-1}$, (c) $1373 \mathrm{~K}, 0.1 \mathrm{~s}^{-1}$, (d) $1473 \mathrm{~K}, 0.1 \mathrm{~s}^{-1}$, (e) $1273 \mathrm{~K}, 0.01 \mathrm{~s}^{-1}$ and (f) $1273 \mathrm{~K}, 1 \mathrm{~s}^{-1}$.

balance of recrystallization nucleation rate and grain growth rate. Grains grow at faster rates at $1473 \mathrm{~K}$ and recrystallization nucleation accelerates at $1 \mathrm{~s}^{-1}$, leading to the finest grains under the deformation condition of $1473 \mathrm{~K}$ and $1 \mathrm{~s}^{-1}$.

\subsection{Fracture morphology}

Fracture morphologies of the studied steel under the strain rate of $0.1 \mathrm{~s}^{-1}$ and at the deformation temperatures of $1173 \mathrm{~K}$, $1273 \mathrm{~K}, 1373 \mathrm{~K}$ and $1473 \mathrm{~K}$ are shown in Fig. 5. The fracture surfaces are all covered with dimples. Figures 5(b), 5(d), 5(f) and $5(\mathrm{~h})$ are the amplified figures of the areas marked by write boxes in Figs. 5(a), 5(c), 5(e) and 5(g), respectively.

Figures 5(a) and 5(b) show that at the deformation temperature of $1173 \mathrm{~K}$, the fracture surface is covered with a large amount of small dimples, and the coalescence of dimples is rarely observed. Internal necking hardly occurs under relatively low deformation temperature, and the deformation tends to generate some microscopic dimples rather than enlarge the previously induced small ones. With the increase of deformation temperature, the coalescence of dimples is most likely to occur. Therefore, a lot of large dimples can be observed on the fracture surface. At the deformation temperature of $1273 \mathrm{~K}$, as shown in Figs. 5(c) and 5(d), the size of dimples is large, and some blade-type edges are distributed on the walls of big dimples, indicating the coalescence of dimples during the hot tensile deformation. When the deformation temperature reaches $1373 \mathrm{~K}$, the dimples become larger, and lots of blade-type edges are observed, shown as Fig. 5(f). At $1473 \mathrm{~K}$, it is observed from Fig. $5(\mathrm{~g})$ that the macroscopic fracture surface is smooth, which is completely different from the macroscopic fracture surface at $1173 \mathrm{~K}$ (shown in Fig. 5(a)). This smooth macroscopic fracture surface is also observed at $1273 \mathrm{~K}$ and $1373 \mathrm{~K}$ (shown in Figs. 5(c) and 5(e)). From Fig. 5(h) it can be seen that the microscopic fracture is covered with equiaxial crystals at $1473 \mathrm{~K}$. This is not the true fracture morphology, because that under high temperature the cross section of necking region decreases, the electric current increases dramatically, and the phenomenon of partial melting appears at fracture surface. 


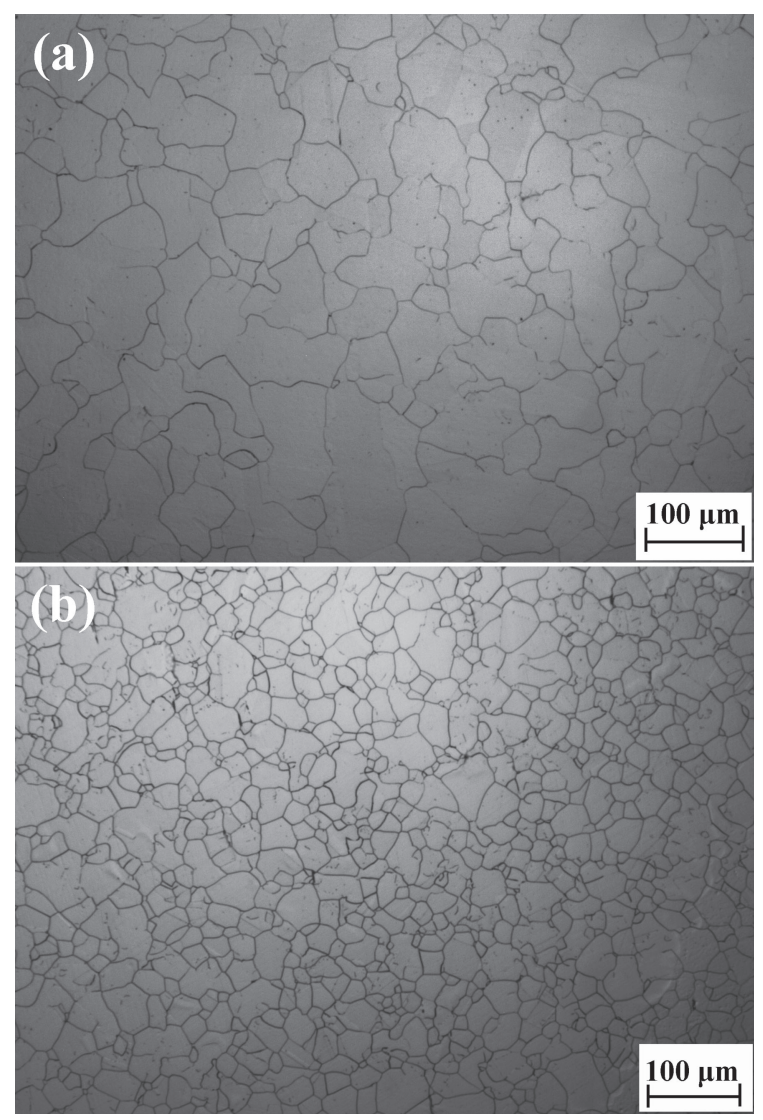

Fig. 4 Metallographic photos of the specimens at the fracture areas: (a) $1473 \mathrm{~K}, 0.01 \mathrm{~s}^{-1}$ and (b) $1473 \mathrm{~K}, 1 \mathrm{~s}^{-1}$.

Figure 6 shows the fracture morphologies of the failure specimens under the deformation temperature of $1373 \mathrm{~K}$ and the strain rates of $0.01 \mathrm{~s}^{-1}$ and $1 \mathrm{~s}^{-1}$. Similarly, Figs. $6(\mathrm{~b})$ and $6(d)$ are the amplified figures of the areas marked by write boxes in Figs. 6(a) and 6(c), respectively. As shown in Figs. 6(b), 5(f) and 6(d), the fracture surfaces are all covered with dimples and tearing edges. It suggests that the nucleation, growth and coalescence of microvoids deteriorate the formability of the studied steel and contribute to the final fracture of specimens at the deformation temperature of $1373 \mathrm{~K}$. Generally, the internal necking resistance of metallic materials increases with the decrease of strain rate, which results in the growth and coalescence of dimples. However, as shown in Fig. 6(d), the size of dimples is small and the coalescence of dimples can rarely be observed. From Figs. 5(f) and 6(b), it can be found that some large dimples appear when the strain rate decreases from $0.1 \mathrm{~s}^{-1}$ to $0.01 \mathrm{~s}^{-1}$. For the case of the strain rate of $0.01 \mathrm{~s}^{-1}$, there is enough time for the growth and coalescence of microvoids. Therefore, the fracture surface is covered with many large dimples.

\subsection{Percentage reduction of area}

Percentage elongation and percentage reduction of area are the two indicators to reflect the plasticity of metals, and usually plasticity of metals is reflected by percentage elongation. In this study, the heating length for specimens during hot tensile tests is not fixed, so the percentage reduction of area of the specimens was calculated to observe plasticity of the studied steel.
Percentage reduction of area of the specimens at different deformation conditions is shown as Fig. 7. Under the deformation temperature range of $1173-1373 \mathrm{~K}$, with the deformation temperature increasing percentage reduction of area increases. While with the strain rate increasing percentage reduction of area firstly increases, and then decreases, percentage reduction of area reaches maximum value at the strain rate of $0.1 \mathrm{~s}^{-1}$. This is an abnormal phenomenon which needs to be further studied. Gittins found that percentage reduction of area of a 302 steel reaches a maximum value at the strain rate of $1 \mathrm{~s}^{-1}$ under the hot tensile temperature of $1373 \mathrm{~K}$, and believed that this phenomenon is related to grain-boundary sliding and dynamic recrystallization (DRX), but under the deformation temperature of $1073 \mathrm{~K}$ there is no DRX occurs and the maximum ductility is absent. ${ }^{26)}$ Under the deformation temperature of $1473 \mathrm{~K}$, with the strain rate increasing percentage reduction of area increases, percentage reduction of area at the strain rate range of $0.01-0.1 \mathrm{~s}^{-1}$ is smaller than that at the same strain rate under the deformation temperature of $1373 \mathrm{~K}$. There are three reasons to explain this phenomenon, one is that under high temperature, the decreasing rate of grain boundary strength is faster than that of intragranular strength, and the fracture mechanism of hot tensile specimens is intergranular fracture, the second is that the recrystallization grains are coarse at high temperature and low strain rate (shown in Figs. 4(a) and 3(d)), which lead to the plasticity decreasing, the last reason is that partial melting appears at fracture surface at high temperature and low strain rate, which results in the decrease of the plasticity at fracture.

\section{Simulation of Fracture Behavior}

Ductile fracture criteria are divided into macroscopic criteria and microscopic criteria. For macroscopic fracture criteria the effects of microstructural evolution are not taken into account, but the equation of which is simple and can be easily calculated and corrected, so they are widely used. Normalized Cockcroft \& Latham criterion is one of the macroscopic fracture criteria and is widely used. It can be expressed as eq. (1): ${ }^{6)}$

$$
\int_{0}^{\bar{\varepsilon}_{\mathrm{f}}} \frac{\sigma^{*}}{\bar{\sigma}} \mathrm{d} \bar{\varepsilon}=C_{\mathrm{f}} \quad \text { in which } \sigma^{*}=\left\{\begin{array}{ll}
\sigma_{1} & \sigma_{1} \geq 0 \\
0 & \sigma_{1}<0
\end{array} .\right.
$$

Where $\bar{\sigma}$ is equivalent stress, $\bar{\varepsilon}$ is equivalent strain, $\bar{\varepsilon}_{\mathrm{f}}$ is the equivalent strain when material fractures (critical fracture strain), $\sigma_{1}$ is maximum principal stress, and $C_{\mathrm{f}}$ is fracture threshold value. Normalized Cockcroft \& Latham criterion supposes that equivalent stress has an effect on the ductile fracture of materials as well as maximum principal stress. Materials fracture when plastic deformation exceeds the fracture threshold value. ${ }^{6}$ )

\subsection{Estimation of fracture threshold values}

Finite element simulation was conducted to determine the facture threshold value for each tensile test. The computations were carried out using DEFORM-3D, a finite element simulation software. The damage parameters were calculated based on the normalized Cockcroft \& Latham criterion. During simulation process, the following three assumptions 

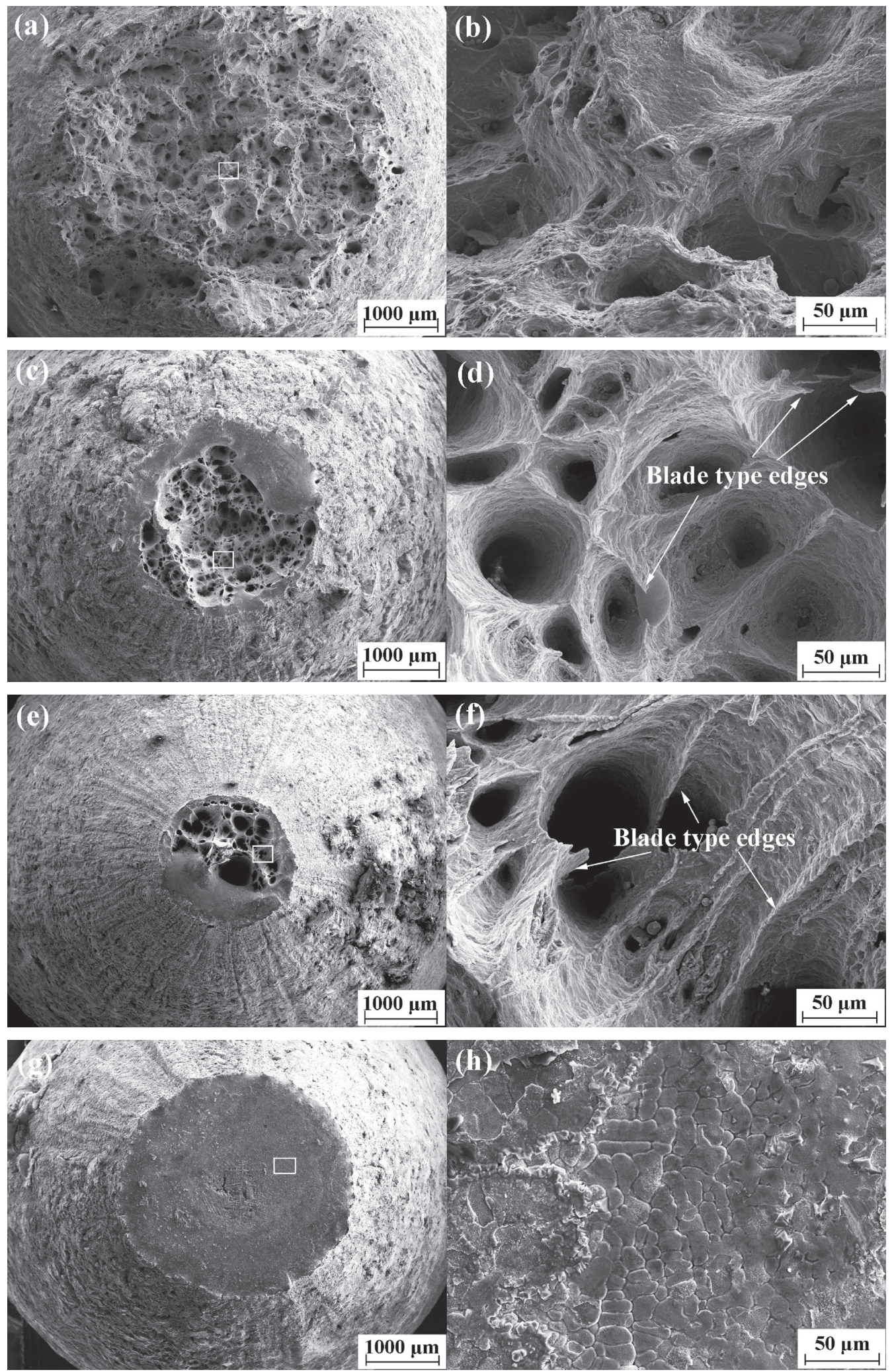

Fig. 5 Fracture morphologies of the specimens deformed under the strain rate of $0.1 \mathrm{~s}^{-1}$ and at the temperatures of: (a) and (b) $1173 \mathrm{~K}$, (c) and (d) $1273 \mathrm{~K}$, (e) and (f) $1373 \mathrm{~K}$, and (g) and (h) $1473 \mathrm{~K}$.

were pre-established: (1) The specimen has only plastic deformation during hot tensile deformation process; (2) The middle part of the specimen is uniform temperature zone (length: $15 \mathrm{~mm}$ ) during hot tensile deformation process, and the temperature of this zone is the specified testing temperature; (3) There is no heat transfer between the specimen and the external environment and no change of mechanical work to thermal energy, so as to keep the temperature of the workpiece constant.

The 3D solid models were built using Pro/Engineer, and then imported into DEFORM-3D software, as shown in Fig. 8. The mesh of the workpiece was generated by 

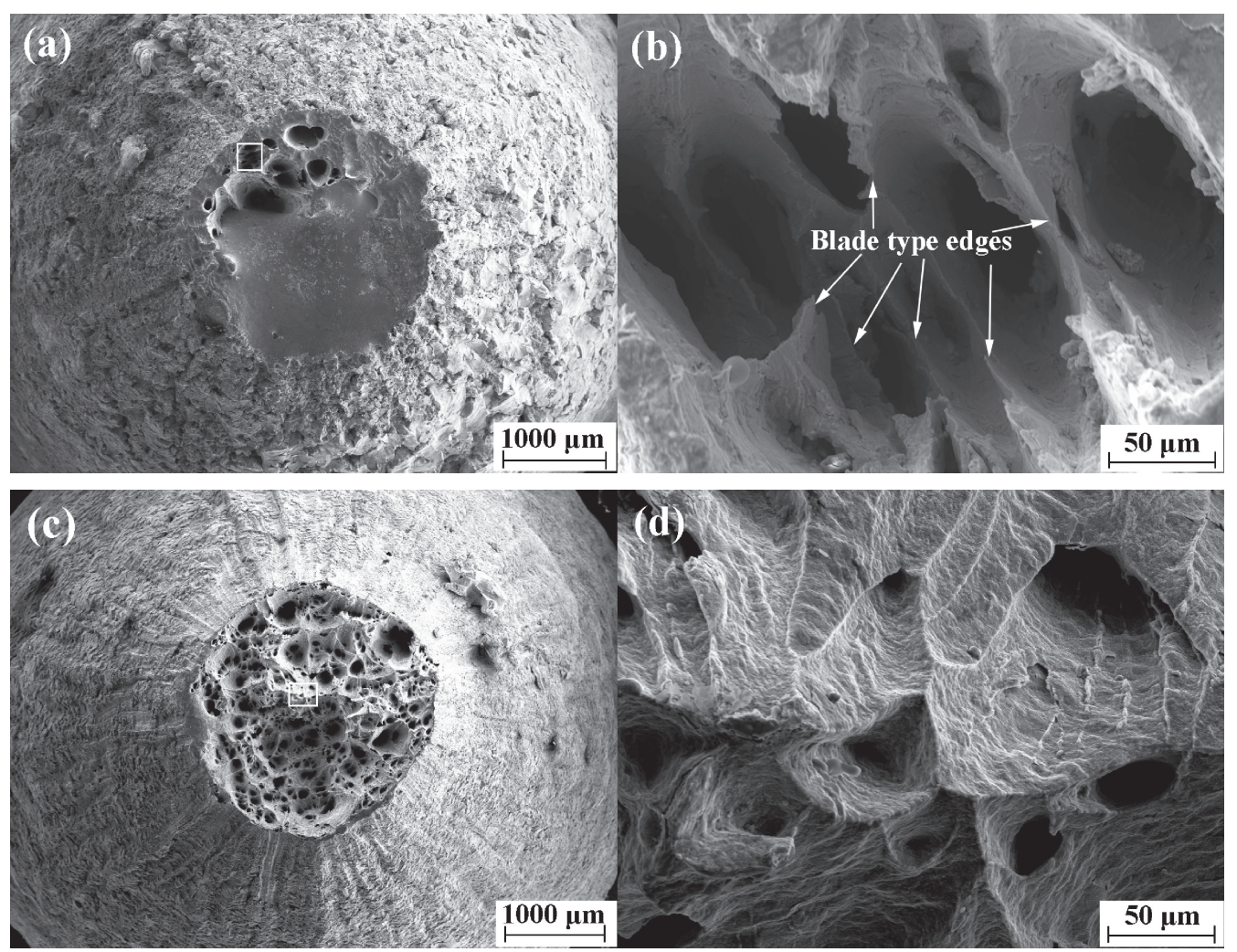

Fig. 6 Fracture morphologies of the specimens deformed at $1373 \mathrm{~K}$ and under the strain rates of: (a) and (b) $0.01 \mathrm{~s}^{-1}$ and (c) and (d) $1 \mathrm{~s}^{-1}$.

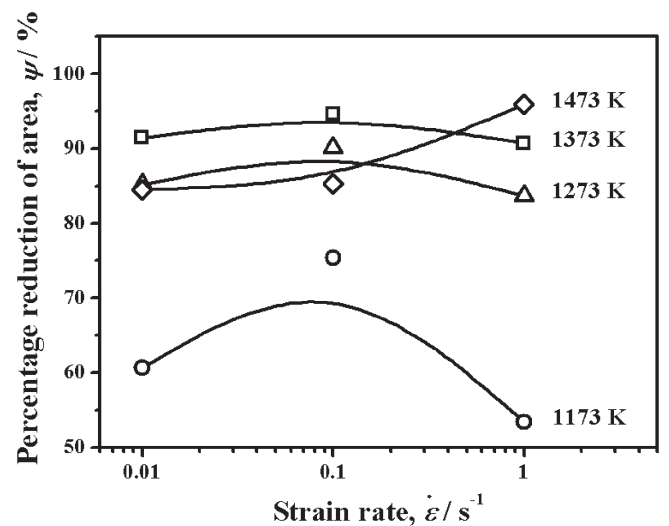

Fig. 7 Percentage reduction of area of the hot tensile specimens.

tetrahedral element, and refined at the center area. The total mesh number of the workpiece is 50000 . The bottom of the workpiece is fixed. The temperature of the top die is the same as the temperature of the workpiece, and the friction coefficient between them is 0.7 . All the other boundary conditions and process conditions are the same with the experimental conditions.

The flow stress-strain curves before necking were obtained directly by the hot tensile experiments, and the flow stressstrain curves after necking were firstly corrected by the Bridgman method ${ }^{27)}$ and Le Roy ${ }^{28)}$ method, and then modified by the heuristic method until the simulated strokeload curves were in agreement with the experimental strokeload curves. The final stroke-load curves exported from the finite element simulation software are compared with the experimental stroke-load curves, as shown in Fig. 9.
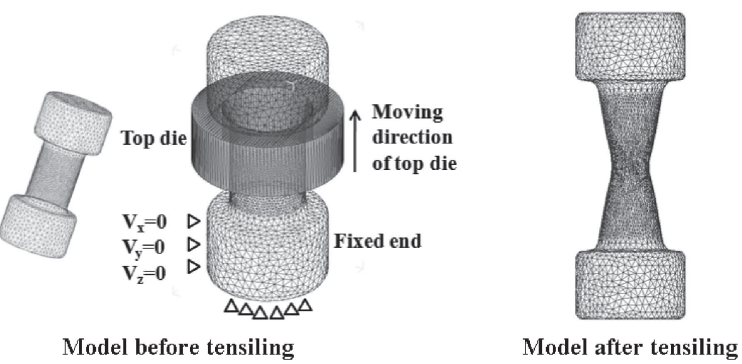

Fig. 8 Solid model of the workpiece and dies before and after tensile simulation.

\subsection{Simulation results and discussion}

The final fracture threshold values of the studied steel calculated by FEM are shown in Table 2. Obviously, the fracture threshold value of the studied steel is affected by deformation temperature and strain rate. Generally, the fracture threshold value increases with the increase of deformation temperature and decrease of strain rate. While normalized Cockcroft \& Latham criterion was proposed based on cold deformation, the effects of temperature and strain rate on fracture threshold value were not included, so it is not suitable for hot deformation.

Alexandrov et al. ${ }^{29)}$ and $\mathrm{Zhu}$ et al. ${ }^{11)}$ believe that the effects of temperature and strain rate on fracture of aluminum alloys and titanium alloy should be considered during hot deformation. The simulation results in Table 2 also show that the fracture threshold value varies with deformation temperature and strain rate. Since the fracture threshold value of the studied steel is affected by deformation temperature and strain rate, it could be expressed by the function of Zener- 

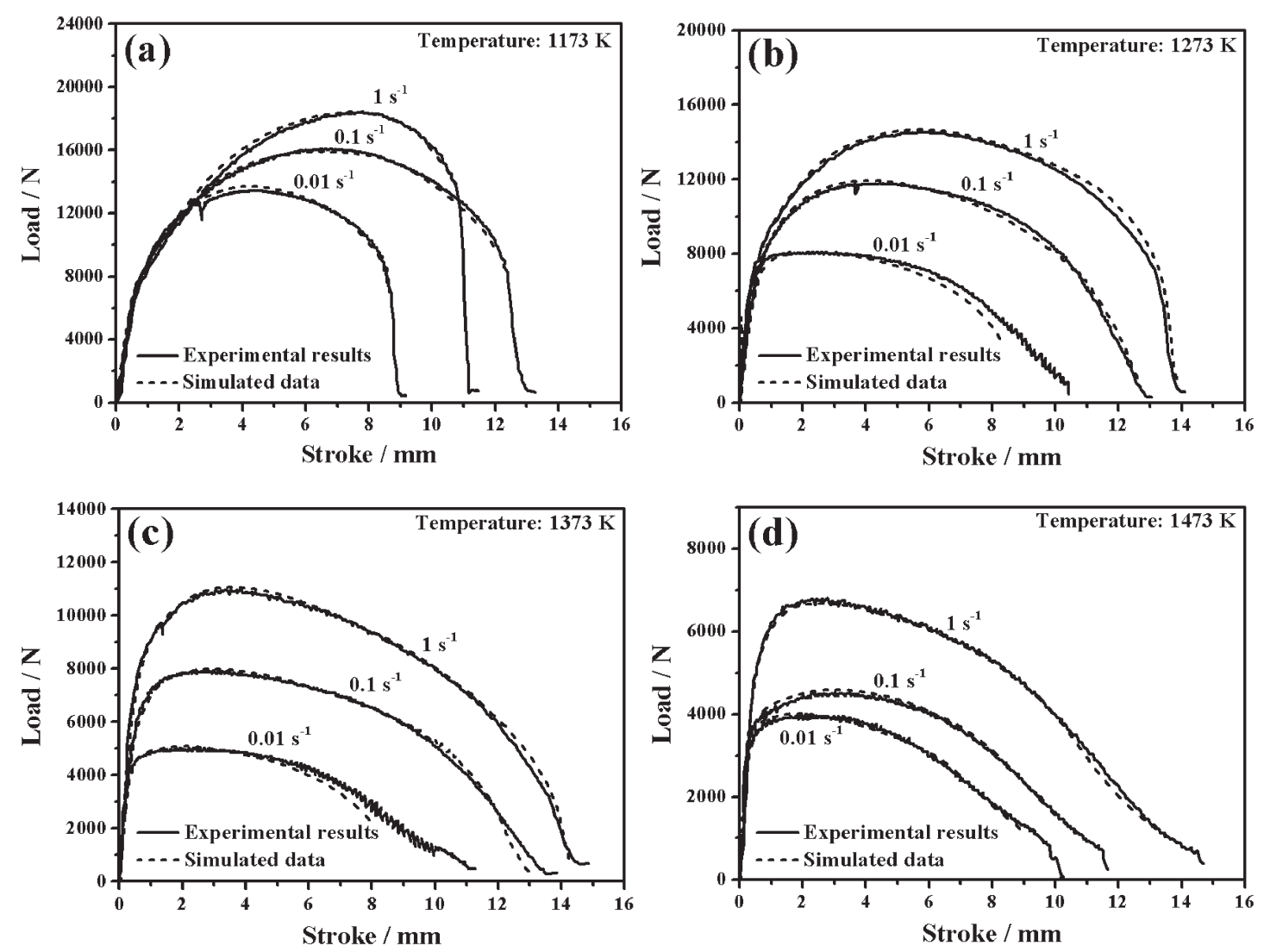

Fig. 9 Comparison between the simulated and experimental stroke-load curves.

Table 2 Fracture threshold values obtained by the finite element method.

\begin{tabular}{ccccc}
\hline Condition & $1173 \mathrm{~K}$ & $1273 \mathrm{~K}$ & $1373 \mathrm{~K}$ & $1473 \mathrm{~K}$ \\
\hline $0.01 \mathrm{~s}^{-1}$ & 0.888 & 1.160 & 1.250 & 1.510 \\
$0.1 \mathrm{~s}^{-1}$ & 0.776 & 0.860 & 1.170 & 1.350 \\
$1 \mathrm{~s}^{-1}$ & 0.717 & 0.945 & 1.050 & 1.450 \\
\hline
\end{tabular}

Hollomom (Z) parameter $(\mathrm{Z}=\dot{\varepsilon} \times \exp (\mathrm{Q} / \mathrm{RT}))$, ${ }^{11)}$ where $R$ is gas constant, $\dot{\varepsilon}$ is strain rate, $Q$ is apparent activation energy of hot deformation, and $T$ is deformation temperature. In our previous study, $Q=472000 \mathrm{~J} / \mathrm{mol} / \mathrm{K}$ is obtained. ${ }^{30)}$ The relationship between fracture threshold value and $\ln Z$ is shown in Fig. 10. It can be seen that the relationship between fracture threshold value and $\ln Z$ is highly linear. Thus, the fracture threshold value of the studied steel, which is based on the normalized Cockcroft \& Latham criterion, can be expressed as eq. (2), and the new fracture criterion can be expressed as eq. (3).

$$
\begin{gathered}
C_{\mathrm{f}}=3.44-0.06 \times \ln Z \\
\int_{0}^{\bar{\varepsilon}_{\mathrm{f}}} \frac{\sigma^{*}}{\bar{\sigma}} d \bar{\varepsilon}=3.44-0.06 \times \ln Z
\end{gathered}
$$

By the new fracture criterion fracture threshold value of the studied steel during hot deformation can be calculated easily and accurately, and the new fracture criterion can be imported into DEFORM-3D by secondary development to predict the fracture behavior of the studied steel during hot deformation. In this study, only the effects of deformation temperature and strain rate are taken account into the

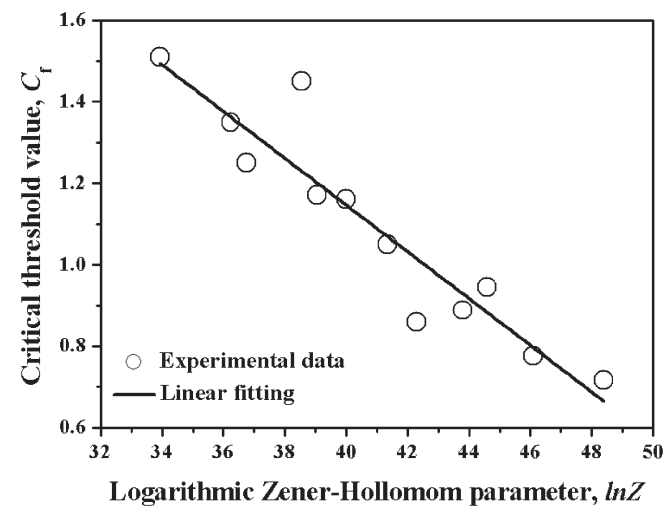

Fig. 10 Relationship between $\ln Z$ and fracture threshold value.

simulation, the effects of microstructure on simulation model are not considered because the mechanism of plasticity during hot deformation are too complex. In order to improve the accuracy of calculation, the effects of microstructure on simulation must be taken into account in the future.

\section{Conclusion}

(1) At the deformation temperature of $1473 \mathrm{~K}$, dynamic recrystallization grains grow rapidly. The coarse grains were observed at the deformation temperature of $1473 \mathrm{~K}$ with the lower strain rates of $0.01-0.1 \mathrm{~s}^{-1}$, while the homogeneous and refining grains were observed at this temperature of $1473 \mathrm{~K}$ but with a higher strain rate of $1 \mathrm{~s}^{-1}$. 
(2) During hot deformation, the effect of decreasing strain rate on fracture morphology is comparable to that of increasing temperature. The size of dimples increased with increasing deformation temperature or decreasing strain rate.

(3) Under the deformation temperatures of 1173-1373 K, the percentage reduction of area of the hot tensile specimens reaches maximum value at the strain rate of $0.1 \mathrm{~s}^{-1}$. At the strain rates of $0.01-0.1 \mathrm{~s}^{-1}$ and under the temperature of $1473 \mathrm{~K}$, the plasticity of hot tensile specimens decreases, if compared to the lower temperature.

(4) Fracture threshold value increased with increasing deformation temperature. A linear relationship was presented between fracture threshold value and $\ln \mathrm{Z}$, i.e., $C_{f}=3.44-0.06 \times \ln Z$.

\section{Acknowledgements}

This work was financially supported by the National HighTech Research and Development Program ("863 Program") of China through grant Nos. 2012AA03A507.

\section{REFERENCES}

1) S. V. S. N. Murty, B. N. Rao and B. P. Kashyap: J. Mater. Process. Technol. 147 (2004) 94-101.

2) A. Venugopal Rao, N. Ramakrishnan and R. Krishnakumar: J. Mater. Process. Technol. 142 (2003) 29-42.

3) B. P. P. A. Gouveia, J. M. C. Rodrigues and P. A. F. Martins: J. Mater. Process. Technol. 101 (2000) 52-63.

4) F. A. Freudenthal: The Inelastic Behavior of Solids, (Wiley, New York, 1950)

5) M. G. Cockcroft and D. J. Latham: J. Inst. Met. 96 (1968) 33-39.

6) S. I. Oh, C. C. Chen and S. Kobayashi: J. Eng. Ind. Trans. ASME 101 (1979) 36-44.
7) P. Brozzo, B. Deluca and R. Rendina: Proc. Seventh Biennial Congress of International Deep Drawing Research Group, (1972).

8) M. Oyane: Bull. JSME 15 (1972) 1507-1513.

9) J. R. Rice and D. M. Tracey: J. Mech. Phys. Solids 17 (1969) 201-217.

10) S. A. Dizaji, H. Darendeliler and B. Kaftanoğlu: Int. J. Mater. Form. (2014) 1-7.

11) Y. C. Zhu, W. D. Zeng, F. S. Zhang, Y. Q. Zhao, X. M. Zhang and K. X. Wang: Mater. Sci. Eng. A 553 (2012) 112-118.

12) X. M. Zhang, W. D. Zeng, Y. Shu, Y. G. Zhou, Y. Q. Zhao, H. Wu and H. Q. Yu: T. Nonferr. Met. Soc. 19 (2009) 267-271.

13) T. S. Cao, C. Bobadilla, P. Montmitonnet and P. O. Bouchard: J. Mater. Process. Technol. 216 (2015) 385-404.

14) J. Q. Ran and M. W. Fu: Int. J. Plast. 61 (2014) 1-16.

15) B. Ahlblom and R. Sandstrom: Int. Mater. Rev. 27 (1982) 1-27.

16) M. J. Luton and W. M. Tegart: Met. Sci. 3 (1969) 142-146.

17) P. J. Wray: J. Appl. Phys. 40 (1969) 4018-4029.

18) M. Zhou, Y. C. Lin, J. Deng and Y. Q. Jiang: Mater. Des. 59 (2014) $141-150$.

19) Y. C. Huang, Y. C. Lin, J. Deng, G. Liu and M. S. Chen: Mater. Des. 53 (2014) 349-356.

20) T. Wang, H. Z. Guo, Y. W. Wang, X. N. Peng, Y. Zhao and Z. K. Yao: Mater. Sci. Eng. A 528 (2011) 2370-2379.

21) F. Mirshahi and M. Meratian: Mater. Des. 33 (2012) 557-562.

22) A. V. Kuznetsov, D. G. Shaysultanov, N. D. Stepanov, G. A. Salishchev and O. N. Senkov: Mater. Sci. Eng. A 533 (2012) 107-118.

23) X. W. Duan and J. S. Liu: Mater. Sci. Eng. A 588 (2013) 265-271.

24) X. Z. Zhang, Y. S. Zhang, Y. J. Li and J. S. Liu: Mater. Sci. Eng. A 559 (2013) 301-306.

25) J. L. He, J. Liu, Z. S. Cui, C. Z. Yang and F. Chen: J. Iron Steel Res. Int. 21 (2014) 923-930.

26) A. Gittins, L. G. Hinton and W. J. McG: Trans. 2 (1973) 199-207.

27) P. W. Bridgman: Studies in Large Plastic Flow and Fracture with Special Emphasis on the Effects of Hydrostatic Pressure, (McGrawHill, New York, 1952) pp. 193-214.

28) G. Le Roy, J. D. Embury, G. Edwards and M. F. Ashby: Acta Metall. 29 (1981) 1509-1522.

29) S. Alexandrov, P. T. Wang and R. E. Roadman: J. Mater. Process. Tech. 160 (2005) 257-265.

30) A. He, G. L. Xie, X. Y. Yang, X. T. Wang and H. L. Zhang: Comput. Mater. Sci. 98 (2015) 64-69. 